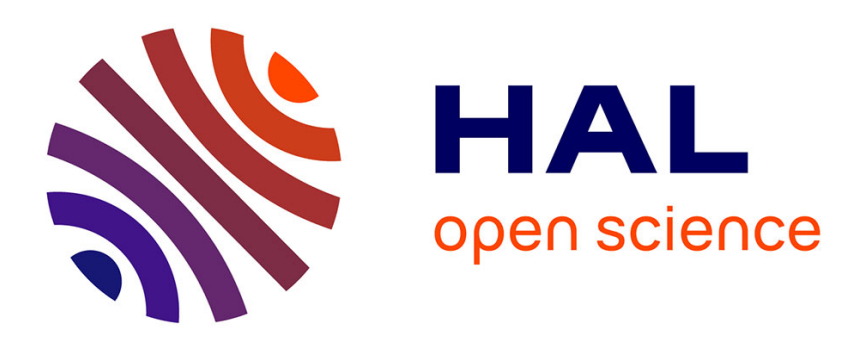

\title{
Coordination of Actinides in Silicate Melts
}

F. Farges, G. Brown, Z. Y. Wu

\section{To cite this version:}

F. Farges, G. Brown, Z. Y. Wu. Coordination of Actinides in Silicate Melts. Journal de Physique IV Proceedings, 1997, 7 (C2), pp.C2-1009-C2-1010. 10.1051/jp4:19972119 . jpa-00255177

\section{HAL Id: jpa-00255177 https://hal.science/jpa-00255177}

Submitted on 1 Jan 1997

HAL is a multi-disciplinary open access archive for the deposit and dissemination of scientific research documents, whether they are published or not. The documents may come from teaching and research institutions in France or abroad, or from public or private research centers.
L'archive ouverte pluridisciplinaire HAL, est destinée au dépôt et à la diffusion de documents scientifiques de niveau recherche, publiés ou non, émanant des établissements d'enseignement et de recherche français ou étrangers, des laboratoires publics ou privés. 


\title{
Coordination of Actinides in Silicate Melts
}

\author{
F. Farges, G.E. Brown Jr.* and Z. Wu
}

Laboratoire de Physique et Mécanique des Géomatériaux, Université de Marne-la vallée (and URA 734 du CNRS and LURE and Stanford University), 93166 Noisy le Grand cedex, France

* Department of Geological \& Environmental Sciences and SSRL, Stanford University, Stanford, CA 94305-2115, U.S.A.

\begin{abstract}
The structural environments around Th(IV) and U(VI) at concentrations ranging from $90 \mathrm{ppm}$ to 7 wt.\% were investigated in glasses and melts of $\mathrm{Na}$ di- and trisilicate compositions between 293 and $1550 \mathrm{~K}$ using $\mathrm{X}$-ray absorption fine structure (XAFS) spectroscopy. Data for model compounds were collected at temperatures up to $2000 \mathrm{~K}$ in order to quantify the magnitude of anharmonic effects. Data for glasses and melts were collected and analyzed considering anharmonic (cumulantexpansion), curved-wave and multiple-scattering effects. In the glasses and melts studied, U(VI) occurs as uranyl groups $[\mathrm{d}(\mathrm{U}(\mathrm{VI})-\mathrm{O} \approx 1.78$ and $2.25(3) \AA]$ and Th(IV) occurs as a mixture of 6 - and 8-coordinated Th at the 1-3 wt.\% Th level, but as 8coordinated Th at trace levels $(90-1000 \mathrm{ppm})$. These two actinides do not undergo significant coordination changes during the glass-to-melt transformation. However, special care in the data analysis protocol is needed to avoid the effects of anharmonicity (due to both positional and thermal effects) which tend to artificially increase the (apparent) amount of 6-coordinated Th.
\end{abstract}

\section{INTRODUCTION}

Naturally occurring actinides (Th and $U$ ) are important trace elements that are used to model the evolution of magmas (molten volcanic rocks) within the deep Earth's crust [1]. These elements are also important in glass-based nuclear wastes. Actinidebearing silicate glasses have long been considered as structural analogs of their molten modifications. In this study, we report the first Th- and U-L III XAFS data collected in-situ; at high temperatures in molten silicates. Th is used to model the behavior of tetravalent actinides (Th and also U(IV)), whereas U is relevant to more oxidized actinide ions that form special complexes (U(VI) as uranyl, $\mathrm{Np}(\mathrm{V})$ as neptunyl, etc.).

\section{EXPERIMENTAL}

Two simple glass compositions were studied: $\mathrm{Na}$-di-, and trisilicate ( $\mathrm{NS} 2: \mathrm{Na}_{2} \mathrm{Si}_{2} \mathrm{O}_{5}$ and NS3: $\mathrm{Na}_{2} \mathrm{Si}_{3} \mathrm{O}_{7}$ ). In parallel, a set of Th(IV) and U(VI) model compounds were examined (e.g., $\mathrm{ThO}_{2}, \alpha-\mathrm{ThSiO}_{2} \mathrm{UO}_{2}$, cuprosklodowskite, $\beta$-uranophane, and others). Th- and U-LIII XAFS spectra for model compounds were collected in transmission mode at LURE (Orsay, France) using the energy dispersive (XAS10) spectrometer and a Si-(311) bent monochromator crystal. We used the heating wire technique to collect XAFS spectra every $20 \mathrm{~K}$ steps, up to $2000 \mathrm{~K}$ [2]. Temperature was measured using an optical pyrometer as well as using a power-temperature calibration based on a set of model compounds melting points. The DCI storage ring was operating at $1.8 \mathrm{GeV}$ and $100-300 \mathrm{~mA}$ positron current. XAFS data for the glasses and melts were collected on beam line 4-3 at SSRL (Stanford) with a Si-(220) two-crystal monochromator; the SPEAR storage ring was operating at $3 \mathrm{GeV}$ and with 50 100 injected electron current. We used a high temperature $\mathrm{Ptg}_{90} \mathrm{Rh}_{10}$ heater to collect XAFS data in the fluorescence mode up to $1550 \mathrm{~K}$ [3]. Temperature was measured in-situ the glass/melt sample by using a Pt:Pt90 Rh 10 thermocouple.

EXAFS spectra were corrected for background absorption using a Victoreen function and normalized for absorbance using a spline fitting. The normalized EXAFS oscillations were converted into k-space by choosing $\mathrm{E}_{0}$ "half-way" up the

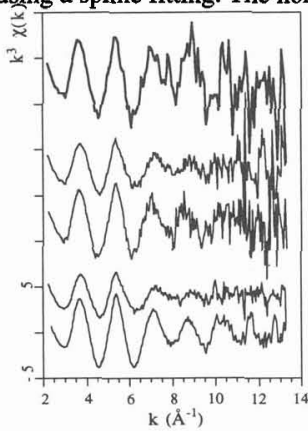

Fig. 1 Normalized Th- $\mathrm{L}_{\text {III }}$ EXAFS for selected glasses and melts (see Fig. 2 for legend).

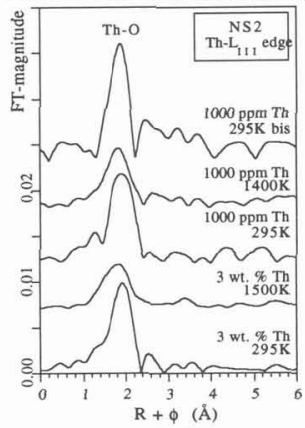

Fig. 2 Fourier Transforms of the Th-LIII EXAFS for selected glasses and melts.

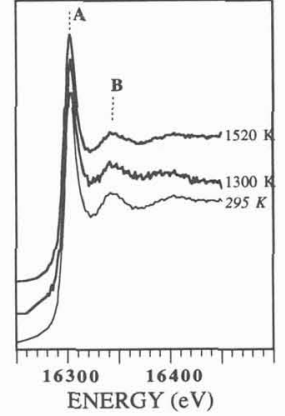

Fig. 3 Th-LIII XANES for NS2 glass and melt with 90 ppm Th.

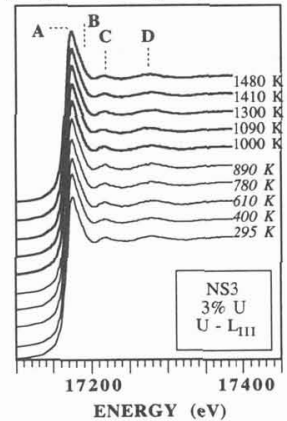

Fig. 4 U-L III XANES for NS2 glass ( $T^{\circ}$ in italic char.) melt ( $\mathrm{T}^{\circ}$ in nonitalic) with 3 wt.\% U(VI). 
absorption jump. The EXAFS oscillations were Fourier Transformed (FT) over the range 3-12 $\AA^{-1}$ using the Kaiser filter and $\mathrm{k}^{3}$-weighted. The contribution arising from $\mathrm{Me}-\mathrm{O}$ pairs $(\mathrm{Me}=\mathrm{Th}$ or $\mathrm{U}$ ) was Fourier filtered in the range $1-2 \AA$ prior to fitting, which utilized a curved-wave, anharmonic (cumulant expansions) formalism [3] that has proven successful in modeling thermal expansion and anharmonicity for Th-O and U-O bonds in the model compounds previously reported, up to $2000 \mathrm{~K}$. Empirical amplitude and backscattering phase-shifts were extracted from $\mathrm{ThO}_{2}$ and uranyl acetate-trihydrate.

\section{RESULTS}

\subsection{Th(IV)}

EXAFS data for model compounds $\alpha$-ThSiO 4 and $\mathrm{ThO}_{2}$ (in which $\mathrm{Th}(\mathrm{IV}$ ) is 8-coordinated) were collected up to $2000 \mathrm{~K}$. There is little evidence for temperature induced-anharmonicity in these compounds, a result that is consistent with the relatively high $\mathrm{Th}-\mathrm{O}$ bond valence ( 0.5 valence units) which results in relatively low thermal expansion coefficients. However, anharmonic EXAFS analysis for Th in melts at appears necessary even though anharmonicity is rather limited.

Figs. 1-3 show typical Th-LIII EXAFS, FT and XANES spectracollected for NS2 glasses and melts with Th-contents between 3 wt.\% and $90 \mathrm{ppm}$. At room temperature, Th(IV) shows average anharmonic Th-O distances of 2.35(3) $\AA$ in NS2 and NS3 glasses with 3-7 wt.\% of Th. This suggests the presence of a mixture of 6- and 8-coordinated Th(IV). Compared to previous work, the present EXAFS results give slightly higher average Th-O distances, suggesting that 6-coordinated Th(IV) may be less important than previously taught. Instead, 8-coordinated Th (IV) appears to be the dominant species. In melts (above $800 \mathrm{~K}$ ), the XANES or EXAFS spectra don't show any changes: Th remains mostly 6- and 8-coordinated in these melts. For glass and melts with lower Th-concentrations $(0.1-1 \%)$, we found that 8-coordinated Th(IV) predominates over 6coordinated Th(IV). We also collected Th-XANES spectra in a melt containing $90 \mathrm{ppm}$ Th at $1520 \mathrm{~K}$. The XANES are similar to that of a glass with $1000 \mathrm{ppm}$ Th, again suggesting that 8-coordinated Th predominates in this melt.

\section{$3.2 \mathrm{U}(\mathrm{VI})$}

Unfortunately, we found that the U-L LII EXAFS data were extremely noisy at temperatures above $600 \mathrm{~K}$; therefore only

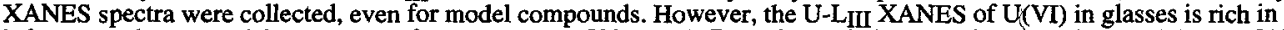
information because of the presence of uranyl groups $\left(\mathrm{UO}_{2} \mathrm{O}_{4-6}\right)$. FEFF6 calculations [4] show that feature $\mathrm{B}$ in the XANES of uranyl complexes (Fig. 4) is due to axial oxygens. At all temperatures, we found this feature to be present at the same position, suggesting little change in the $U-O_{a x i a l}$ distance for glasses and melts $(\approx 1.78 \AA)$. This result suggests that uranyl groups are also present in the molten state, in an environment similar to that of the glass. Also, changes in the U-concentration (0.2-7 wt. range) don't have a significant effect on the the U-LMI XANES, confirming again the high stability of these uranyl complexes in the melts studied here.

\section{DISCUSSION}

Compared to their glassy modifications, we observed little changes in the coordination environment of Th(IV) and U(VI) in NS2 and NS3 melts in the 700-1550 K range for actinide concentrations ranging from 0.01 to $7 \mathrm{wt} \%$. Th(IV) is mostly 6- and 8-coordinated but, surprisingly the 8-coordinated Th species dominates at lower Th-contents. This coordination chemistry is very similar to that observed for synthetic glasses simulating natural magmas where a mixture for 6-and 8-coordinated Th was detected [1]. This suggests that natural magmas (in which the Th-concentration is around the ppm level) may containmainly 8-coordinated Th(TV). Six-coordinated Th(IV) has been reported for nuclear waste glasses (which have a composition not far from NS2 and NS3) [5]. The present study indicates that 6-coordinated Th(IV)may also be important in these systems. Also increasing temperature does not promote any nucleation around Th or U in NS2 and NS3.

\section{Acknowledgments}

The authors thanks D. Andrault and P.E. Petit (IPGP) and the staffs of SSRL and LURE, particularly F. Baudelet and J-P Itie of XAS10 beamstation. Work was supported by U.S. NSF grant EAR-9305028 (Brown) and by French DBT/INSU (CNRS).

\section{References}

[1] Farges F., Geochim. Cosmochim. Acta 55 (1991) 3303-3319; Farges F., Ponader C., Calas G. and Brown G.E. Jr,Geochim. Cosmochim. Acta 56 (1992) $4205-4220$ (see also references therein).

[2] Farges F., Fiquet G., Itie J.-P. and Andrault D., Nucl. Instr. Meth. Phys. 101 (1995), 493-498.

[3] Farges F., Brown G.E. Jr., Navrotsky A., Gan H. and Rehr J.J., Geochim. Cosmochim. Acta 60 (1996), 3023-3065 (3 papers).

[4] Zabinsky S.I., Rehr J.J., Ankudinov A., Albers R.C. and Eller M.J., Phys. Rev. B 52 (1995), 2995-3009.

[5] Veal B.W., Mundy J.N. and Lam D.J., Actinides in silicate glasses, "Handbook on the Physics and Chemistry of the Actinides", (A.J. Freeman and G.H. Lander, Eds.), pp. 271-309. Elsevier. 